\title{
El cabildo de Cartagena de Indias, una pandilla dominada por Vicente de Peñalosa, 1675-1680
}

Julián B. Ruiz Rivera

Universidad de Sevilla (España) 



\title{
El cabildo de Cartagena de Indias, una pandilla dominada por Vicente de Peñalosa, 1675-1680
}

\section{Cartagena de Indias City Council, a gang under the dominance of Vicente de Peñalosa, 1675-1680}

\author{
Julián B. Ruiz Rivera \\ Universidad de Sevilla (España) \\ jbruiz@us.es
}

Fecha de recepción: 8 de diciembre de 2020

Fecha de aceptación: 20 de abril de 2021

\section{Resumen}

Se trata de un estudio de caso en el cabildo de Cartagena de Indias: la pugna entre el regidor Vicente de Peñalosa y el teniente general Domingo de la Rocha, el primero sin estudios y el segundo licenciado en Cánones. El primero atesoraba unos antepasados con muchos servicios a la Corona y en las conquistas. Peñalosa comenzó por la tierra donde sus antepasados habían protagonizado sus hazañas, en Mompox, que no le resultó suficiente y quiso dar el salto a Cartagena como escribano. Las opiniones de los vecinos no pudieron ser más negativos: inquieto, revoltoso, pleitista y sedicioso. No obstante, Peñalosa tenía dos cédulas reales que lo avalaban, pero el cabildo recurrió al Consejo de Indias y no consiguió ser escribano. Pero gracias a sus amistades logró ser elegido regidor de Cartagena, donde logró dominar el cabildo, contra la opinión del teniente general, que realizó algunas reformas en el mercado. Pagó 550 pesos por un regimiento perpetuo, que no consta fuera confirmado, aunque en su enfrentamiento con de la Rocha logró que el que ya había ascendido a oidor de Santa Fe fuera condenado en una causa judicial con Peñalosa e incluso a pagar las costas del juicio. De nada sirvieron los inmejorables informes sobre de la Rocha frente a las influencias cortesanas de Peñalosa.

Palabras clave: Cartagena de Indias; Vicente de Peñalosa; Domingo de la Rocha

\begin{abstract}
This is a case study in the city council of Cartagena de Indias: the conflict between the councilor Vicente de Peñalosa and the legal councelor (teniente general) Domingo de la Rocha, the first one without a University title and the second one with a Law title by Salamanca. The former one accumulated ancestors with many
\end{abstract}


El cabildo de Cartagena de Indias, una pandilla dominada... - J.B. Ruiz Rivera

military services and merits in conquests. Peñalosa started out where his ancestors had stared in their feats, in Mompox, where he did not feel completely realized and tried to jump to Cartagena as notary. His neighbours, however, put down very negatives opinions about him: restless, unruly, litigious and seditious. Nontheless, Peñalosa had two royal letters that backed him, but the City Council appealed to the Council of the Indies in Madrid and Peñalosa did not get the post. But by means of friends he got to be elected councilor of the city of Cartagena, in which he dominated the rest of the gang, having always in front the governor's legal counsellor, who introduced some reforms in the city market. He paid 550 pesos for the seat in the City Council without time limit, which was never confirmed, although in the confrontation with de la Rocha, already promoted to the post of judge in Santa Fe, he got a positive sentence in a judicial case with Peñalosa, which obliged the counterpart to pay the legal costs. Of no use were the insuperable informs about de la Rocha against the courtly influences of Peñalosa.

Keywords: Cartagena de Indias; Vicente de Peñalosa; Domingo de la Rocha.

Así denominaba el también regidor de la ciudad de Cartagena de Indias -en adelante solo Cartagena, pues ya sabemos a lo que nos referimos- Martín de Buitrago Salazar la situación a la que había llegado el cabildo de la ciudad, después de haber tenido que sufrir durante los primeros años de la década de 1670 las descortesías y agravios del gobernador Pedro de Ulloa Ribadeneira, que insultaba, agredía y, con total impunidad mandaba poner en detención a varios regidores en castillos o en la cárcel sin ninguna consideración a su categoría y dignidad:

nos trata en el Cabildo con palabras tan feas como indignas de la reverencia al Cuerpo de una Ciudad, que por indecentes y ajenas a los oídos de V.M. no las referimos, solicitando causas para privarnos los votos, porque queremos obrar con libertad en las utilidades de la república y en las elecciones de alcaldes y oficios. ${ }^{1}$

Pandilla es bastante fuerte y, desde luego, despectivo y ofensivo, aunque tampoco nos puede llevar a escándalo conociendo los gobernadores que presidieron el gobierno en aquella década, Ulloa Ribadeneira destituido y condenado en la residencia en 2.000 pesos que luego se le rebajaron y José Daza Guzmán destituido y enviado preso a la península, donde permaneció en la cárcel de la Casa de la Contratación hasta que se le suavizó a prisión domiciliaria. ¿Qué se podía esperar con tales mandatarios? El cabildo vivió una deserción en masa bajo Ulloa pues nadie quería comprar un oficio de regidor para tener que soportar los arrebatos o castigos del superior solo por discutirle la conveniencia de determinadas decisiones, de modo que en este contexto cualquier cosa podía sobrevenir, hasta la de caer en manos de una pandilla y un aventurero.

1 AGI, Santa Fe, 44, R.1, N.20, imag. 6. Representación a la Reina de los regidores López de Medina, Echarri, Bosque, Buitrago, Matute, Núñez de León y Olivera y Cervantes, Cartagena, 25 nov. 1670. 
La historia de los cabildos indianos, bien podemos decir, es lo más medular de la historia del Nuevo Mundo, pues en ellos se encarna la mayor realidad de la población que hacía frente a su cuotidiano vivir en el marco que les imponían las élites, bien del gobierno superior de Santa Fe o del supremo de Madrid, bien del propio municipio. Ahora bien, así considerada esa historia es tan vasta que en gran medida se confunde con la historia total de América. En el caso de Cartagena, a todo eso se añade el haber perdido toda la documentación municipal. Porque una cosa es lo institucional de los cabildos, los cargos, su regulación jurídica, sus competencias, sus responsabilidades, pero otra muy distinta es su desarrollo real, el grado de cumplimiento de las leyes y las desviaciones al amparo de la distancia y de la corrupción de los individuos, que en el caso de Cartagena y, en especial del siglo XVII, es muy desconocido. El tema de los cabildos es sumamente extenso, como puede observarse en quien ha profundizado en ello, José Luis Caño Ortigosa. (Caño Ortigosa, 2019a y 2019b). En los tiempos que vivimos de pandemia las dificultades para la consulta bibliográfica se han multiplicado, incluso sin considerar la carencia de obras elaboradas.

En este caso se trae a consideración el choque dentro de la ciudad de Cartagena entre el cabildo, dominado por un grupito de regidores bajo la batuta de un individuo por muchos motivos sospechoso y, de otro lado, la autoridad provincial del gobernador $\mathrm{y}$, en este caso de su asesor legal, el teniente de gobernador, que estaba decidido a poner coto a determinados abusos del mercado conectados con la corrupción.

Cuando en una misma ciudad coincidían el gobernador y el gobierno municipal solían producirse esos desencuentros. En el caso de Cartagena se agudizaban dado que contaba con una plaza fuerte con guarnición y amenaza latente de enemigos que en cada uno de los tres siglos se convirtió en ataque real, pues la ciudad fue asaltada un par de veces por franceses en el siglo XVI y, sobre todo, por el inglés Francis Drake, en el siglo XVII por el Barón de Pointis y en el siglo XVIII sin éxito por el almirante inglés William Vernon. La desproporción de responsabilidades y de poder entre el gobernador y el cabildo era inmensa. Esta situación convirtió a la ciudad en muy dependiente del gobierno metropolitano y, por consiguiente, del gobernador y relegó al cabildo a una situación de dependencia muy acusada por motivos de seguridad mayormente.

Dos ejemplos pueden ilustrar esta relación desigual. El primero en los años 1630 con el autoritario y un poco agrio gobernador Francisco de Murga, muy eficaz en su competencia de experimentado militar para fortificar la plaza, que trataba con descortesía y vocabulario impropio a los regidores, lo que le valió una reprimenda del Consejo. El segundo, el mencionado gobernador Pedro de Ulloa Ribadeneira que no se quedaba sólo en palabras, sino que arrestaba al que le contradijera y el cabildo se quedó mermado de aspirantes. En fin, que las relaciones entre una y otra institución no fueron fáciles.

Aquí se trae un estudio de caso, basado en documentación del Archivo General de Indias, en que se produjo ese choque personificado en el teniente de gobernador, 
Domingo de la Rocha Ferrer, un canario tinerfeño graduado en Salamanca, y un gaditano, Vicente de Peñalosa Molina, híbrido de criollo y madre peninsular que creció en Cádiz con influencia americana. Tenía mucha labia, en lenguaje de la época, verbosidad, nada sorprendente en dicha ciudad. Solicitó y se le concedió un regimiento perpetuo, pero lo cierto es que no consta la confirmación para la que contó con cinco años de plazo, mas en la correspondencia del cabildo tan sólo figura su firma en los años 1675, 1677 y 1679. Tampoco consta que tuviera estudios. En este caso no sólo se midieron las opiniones del cabildo y de la ciudad, sino el grado de influencias que Peñalosa disfrutó en la Audiencia de Santa Fe y en la corte de Madrid gracias al historial de sus antepasados que acumulaban méritos de conquista y prolongados servicios militares.

\section{VICENTE DE PEÑALOSA}

Nació en Cádiz de padre momposino y madre gaditana. La saga de los Peñalosas venía de antiguo, pues otro Vicente de Peñalosa obtuvo el 19 de febrero de 1609 el cargo de alguacil mayor con poder para nombrar a sus tenientes y alcaldes de las cárceles. ${ }^{2}$ Era hijo legítimo de Diego de Peñalosa, natural de la villa de Mompox y de Doña Isabel de Molina, natural de Cádiz. Ella era hija legítima del capitán Lucas de Molina "uno de los veinte de infantería del número de la Armada Real del Mar Océano."

Vicente de Peñalosa era el único heredero legítimo de Diego, a su vez hijo legítimo de Alonso Sánchez Peñalosa y de Doña Gerónima de Veleña, que fue hija legítima del capitán Juan de Veleña, teniente de Gobernación y teniente de Capitán General, Justicia Mayor y Juez de Canoas de la villa de Mompox y de Doña María de Ayala, su legítima mujer, y la sobredicha hija legítima del capitán Alonso López de Ayala, uno de los principales conquistadores de esa ciudad y provincia. El gobernador Diego de Acuña concedió el 10 de enero de 1619 una encomienda al capitán Fernán Pereira de Castro, esposo de Doña Juana de Veleña, hermana de la abuela de Vicente de Peñalosa, por donde consta ser sus antepasados encomenderos y conquistadores.

El capitán Juan de Veleña, hombre noble, hijodalgo de notoria ejecutoria, que se halló en todas las ocasiones de conquista y allanamiento de indios y defensa de la ciudad contra piratas corsarios, cuyo título se confirmó en Madrid a 27 de enero de 1620. Asimismo se le acumuló el título de encomienda dado por el gobernador Pedro Fernández de Busto al capitán Juan de Veleña, natural de la Villa de Medina del Campo, por haber servido veintidós años en la gobernación de Cartagena y en la de Santa Marta en la pacificación de los indios y contra los corsarios, en especial

2 AGI, Santa Fe, 160, N. 5, imag. 165. Expediente de alguacil mayor de Martín de Mirafuentes. 1674.

3 AGI, Santa Fe, 160, N. 9, imag. 75. Expediente de regidor perpetuo de Vicente de Peñalosa, 1675. 
en la ciudad de Cartagena, en concreto en el fuerte de la Caleta con diez soldados, las personas y armas a su costa, por lo que recibió título de diversos repartimientos en Mompox a 28 de abril de 1578, como figura en la historia de esta provincia escrita por Fr. Pedro Simón, Provincial que fue de la orden de San Francisco, en los capítulos que se refieren a los servicios que hicieron los dichos capitanes Juan de Veleña y Alonso López de Ayala en los descubrimientos y conquistas de esta provincia y de la de Santa Marta, sacado con autoridad de Justicia por el escribano Bartolomé de Salinas en 27 de septiembre de $1654 .^{4}$

El tatarabuelo de Vicente de Peñalosa, Alonso López de Ayala, había sido regidor de Cartagena en 1562, según testimonio de 5 de octubre de 1673. Su abuelo, el capitán Lucas de Molina, por sus servicios de veintinueve años en el mar recibió la merced de 24 escudos de entretenimiento al mes en una cédula dirigida al Marqués de Villanueva de Valduesa, capitán general de la Real Armada en 28 de agosto de 1633. El mismo en un encuentro que tuvo el 10 de agosto de 1621 la Armada Real al mando de Don Fadrique de Toledo Osorio con la armada holandesa en el estrecho de Gibraltar, por señalarse peleando y apresando algunas naves del enemigo, se le incrementó en un escudo al mes de por vida desde el día de la batalla, según cédula de San Lorenzo, 29 de octubre de 1624. El mismo capitán Molina el 16 de agosto de 1634 fue elegido en octavo lugar entre los veinte capitanes de infantería de la Real Armada. Otra real cédula dirigida al Duque de Medina Sidonia, capitán general de la Real Armada del Mar Océano le destinó al presidio de la ciudad de Cádiz manteniéndole el mismo sueldo en 28 de noviembre de 1638.

Tras su ida a Mompox, -según un testigo, se vino de España por una falsedad que hizo en Cádiz en un oficio de escribano- el capitán Vicente de Peñalosa fue electo el $1^{\circ}$ de enero de 1654 alcalde de la Santa Hermandad y nombrado por el gobernador Pedro Zapata alférez de una de las compañías de Mompox en 1657 y elegido alcalde de la Santa Hermandad de la villa el año 1664 y más tarde regidor y fiel ejecutor, según testimonio de 1665. El gobernador Benito de Figueroa y Barrantes lo nombró capitán de las armas de Mompox el 26 de noviembre de 1666, que luego refrendaron los gobernadores Vergara y Azcárate y Ulloa Ribadeneira. En 1672 se presentó con un nombramiento de teniente de fiel ejecutor que le hizo José Álvaro Evangelista que era el propietario, nombramiento que le refrendó el gobernador Don Diego de Portugal por el que presentó 28 pesos, 8 reales y 20 maravedíes en pago de la media anata. En el mismo año fue nombrado procurador general de dicha villa, hizo juramento y prometió usar bien del cargo. Ulloa lo nombró en 1673 sargento mayor de la villa de Mompox, por lo que pagó la media anata y fue recibido en el cabildo el 14 de enero. El gobernador Ulloa encargado de las residencias de Mompox por encargo del visitador Don Jacinto de Vargas Campuzano no encontró nada irregular en el ejercicio de escribano de Cabildo de Vicente de Peñalosa, ni hubo querella ni

4 AGI, Santa Fe, 160, N. 9, imags. 77-78. 
demanda, según auto firmado en 28 de noviembre de $1674 .{ }^{5}$ Da fe de ello Francisco de Corpas, teniente de escribano público. Esta buena relación con el gobernador Ulloa ya de por sí levanta algunas sospechas sobre el papel que jugaba en la villa al servicio de su superior en la ciudad. Por el desempeño de los oficios de regidor, fiel ejecutor y procurador general fue condenado en la residencia en 60 pesos y en las costas y en lo demás había cumplido, según testimonio del escribano de 8 de diciembre de 1674.

Cargos que le hicieron a Vicente de Peñalosa en la residencia que le tomó Pedro de Ulloa por encargo del visitador Jacinto de Vargas Campuzano:

1. No hizo juntas del cabildo de Mompox;

2. No eligió en el cabildo alcalde de bienes de difuntos cada año;

3. Faltó a un montón de sesiones de cabildo que vienen especificadas.

Peñalosa pidió ser dado por libre de dichos cargos, aunque le declararon culpable de los tres y por el $3^{\circ}$ le pusieron una multa de 2.000 maravedíes, poco más de 4 pesos, según sentencia de 20 de octubre de 1669 por el cargo de fiel ejecutor de la villa de Santa Cruz de Mompox.

Cargos como alcalde de la Santa Hermandad de la villa de Mompox que realizó el juez de residencia Don Pedro Polo en la residencia del gobernador Pedro Zapata y todos sus tenientes por comisión de Don Antonio Abello y Valdés, alcalde de corte en la Real Chancillería de Valladolid y visitador general de la Audiencia de Panamá y Tierra Firme.

Contra el contador Vicente de Peñalosa, alcalde de la Santa Hermandad:

$1^{\circ}$ En compañía de Antonio de Espinosa, su compañero, multaron a tres negros cimarrones el 19 de enero de 1654 en 60 pesos y no consta que apartaran lo correspondiente para la Cámara de S. M.

$2^{\circ}$ Tampoco mantuvo libro ni caja de la Hermandad

Se reservó hacer otros cargos, hasta sustanciar estos primeros. Pedro Polo en Mompox, a 2 de abril de 1659.

Se puede decir, por tanto, que había conquistado Mompox, la tierra donde habían destacado sus antepasados, aunque él fuera nuevo en la villa. Pasar de Cádiz a Mompox casi con toda seguridad le debió producir un choque que tuvo sus consecuencias insuficientemente contrapesadas por los numerosos nombramientos. ¿Cómo se comportó para que le tiraran una lanzada al cuello que a punto estuvo de arrebatarle la vida? Estaba soltero, no tenía bienes raíces ni móviles y todo dependía de su persona. ¿Por qué creó tantas enemistades por donde quiera que pasó, Mompox, Tenerife o Santa Marta, por no mencionar Cartagena? No tendría bienes,

5 AGI, Santa Fe, 160, N. 9, imags. 84-85. 
pero ambición no le faltaba. Hemos visto cómo fue escalando en Mompox, que no le parecía suficiente para sus dotes. Intentó ganarse Santa Marta, aunque sus miras estaban puestas en Cartagena naturalmente. Vamos a ir por pasos.

\section{EL SALTO A CARTAGENA Y LOS OBSTÁCULOS}

De todos los cargos que había ocupado en Mompox ninguno le podía servir para dar el salto a Cartagena, salvo quizás uno, el de escribano real. ¿Pero valía lo mismo en una villa que en la ciudad de mayor cantidad y calidad de negocios? Lo podía intentar y lo intentó presentándose para que lo examinaran. Cuál no sería su fama que hubo una férrea oposición a que se presentara para el examen. No se les debía ocultar a los cartageneros el apoyo que sin duda tenía en la corte y en la Audiencia de Santa Fe para conseguir sus fines. Viniendo del Sur y, concretamente de Cádiz, no le faltaba el don de palabra y facilidad de argumentos con que enredar al contrincante. Lo cierto es que la mera posibilidad de tenerlo como escribano levantó una oposición cerrada en el seno del cabildo, pues mucho se temían que el siguiente movimiento sería conseguir una plaza en el cabildo.

A Francisco Ximénez Enciso, maestro de campo, le había presentado Vicente de Peñalosa una cédula del rey, en la que le autorizaba para ser examinado de escribano cuando se tenían noticias de que en el desempeño de un oficio en Cádiz había cometido alguna irregularidad que le forzó a huir de allí, por lo que solicitaba que se tuviera en cuenta ese hecho y que allí no tenía casa ni domicilio estable ni hacienda y andaba vagando de unas partes a otras y que Martín Sánchez de Aguilar, escribano de cabildo y de gobernación de Santa Marta le presentó un escrito con el juramento necesario en que constaba su mal natural y proceder que no convenía al servicio de Dios y de Su Majestad. ${ }^{6}$ Ante dichos hechos, el teniente general de Cartagena, Don Lope de Cevallos Barreda suspendió la ejecución de la cédula hasta presentar al rey las alegaciones y que decidiera lo mejor en justicia, a 4 de septiembre de 1664.

El procurador general de la ciudad de Cartagena, Juan de Uriarte Araoz expuso que no convenía recibirlo a examen porque era de natural inquieto y ruidoso, pues ya era sospechoso cuando llegó de España porque había salido huyendo de Cádiz antes de que lo apresaran las autoridades. Cuando llegó a Mompox lo recibieron tan mal que una noche un mulato pagado por un vecino le dio una lanzada en el cuello, de que todavía tenía la cicatriz, y se vio tan mal que prometió hacerse fraile de San Diego, pero los frailes no lo admitieron. Pero surge la duda: si lo recibieron tan mal ¿cómo es que le dieron tantos cargos como se han mencionado? ¿No será que los cartageneros estaban exagerando? Dos veces, prosigue el procurador Uriarte, lo trajeron preso a Cartagena con grilletes por orden de los tenientes generales.

6 AGI, Santa Fe, 45, R. 1, N. 48, imag. 80. Domingo de la Rocha Ferrer a S.M., Cartagena, 3 sept. 1679. 
Ante ese cúmulo de dificultades, Peñalosa emigró a Santa Marta donde por tener revuelta la ciudad lo desterraron por decisión del gobernador Marcos del Puerto con la anuencia del obispo. Esta petición de no admitirlo a examen, que no podía cursarla el procurador general, sí podía ponerla cualquier vecino con el fin de limpiar la tierra de magistrados tumultuosos y sediciosos. ${ }^{7}$

Con el teniente general Domingo de la Rocha ya había tenido desencuentros a propósito de la inspección que el teniente general planteó de las carnicerías, pescaderías y panaderías para revisar los pesos, a la que se opusieron los regidores de cuyo líder opinaba esto el teniente general de la Rocha:

este sujeto, Señor, es tan malo que se ha experimentado que desde que está en Cartagena no hay quietud en su república introduciendo pleitos y disturbios entre sus vecinos, defendiendo a ambas partes, porque se ha metido a letrado siendo un pobre romancista, que aun el castellano no lo entiende, haciendo con esto que las partes ignoren el derecho de su justicia errándoles la acción que les compete a sus defensas y no sólo es este el mayor delito sino el desdoro que padecen los ministros de V.M. así eclesiásticos como seglares por este hombre que estando dos veces preso para desterrarlo, al tiempo de ejecutarlo se han muerto dos tenientes generales antecesores míos, como consta en los autos adonde me remito a instancias de este Peñalosa y de otros. Se ha introducido que de cualquier auto que doy o sentencia, si no les es muy favorable a las partes, se presentan ante el Gobernador con el pretexto de recurso o agravio y se me quitan los autos y el Gobernador por sí y otras con parecer de abogados determinan mi auto o sentencia unas veces confirmándolas y otras revocándolas como remito algunos testimonios, originándose de aquí gravísimos inconvenientes, pues lo primero siendo la jurisdicción del Gobernador lo mismo que la de su teniente no puede revocar ni conocer del agravio de la sentencia o auto dado por mí, principios claros de derecho; lo otro, que se hacen cuatro instancias con la de la Audiencia, una la de los alcaldes, otra de ellos a mí, otra al Gobernador y otra a la Audiencia que con consulta de tan grandes ministros como V.M. tiene en su Real Consejo hallará es repugnante a todo derecho; lo otro que abriéndose la puerta a este abuso, todo será tropelía, con que las causas se perpetuarán. ${ }^{8}$

Con esto ya iba bien servido el aspirante Peñalosa, pero hubo más testimonios. Manuel Fernández de Aponte, sargento del capitán Juan Polo del Águila, lo conoce desde hace diez años y conduciendo ganado de cerda desde Mompox lo vio malherido y la gente diciendo que lo habían de matar, aunque se refugiase en una iglesia, porque inquietaba a la república y en otra ocasión, estando en la Barranca, lo vio pasar que lo llevaban preso a Cartagena. Sería muy malo de escribano porque es de natural

7 AGI, Santa Fe, 45, R. 1, N. 48, imags. 73-75. Domingo de la Rocha Ferrer, teniente general a S.M., Cartagena, 3 sept. 1679

8 AGI, Santa Fe, 45, R. 1, N. 48, imags. 1-2. 
muy malo, revolvería la república porque es pleitista, inquieto y tumultuoso. No tiene vecindad y anda vagando, pues sólo tiene su persona. ${ }^{9}$

Juan Rodríguez Vidal lo conoce de hace cinco años y le ha visto en la ciudad y en la villa de Tenerife. Es amigo de revoluciones e inquietudes y de natural ruidoso. En una ocasión el testigo fue a Tenerife con un hermano de Domingo Puche Montenegro y estando ellos hablando alguien dijo que andaba por la villa Vicente de Peñalosa y Domingo dijo que más valdría que estuviera quemado porque había habido un ruido por el que le dieron una lanzada en el pescuezo. De escribano siendo tan pleitista sería muy malo. Por sus inquietudes fue traído preso a la ciudad. ${ }^{10}$

Juan Calvillo lo conoce y ha oído en Mompox y en Santa Fe que es hombre pleitista y amigo de hacer peticiones. Llegó una que provocó que le expulsasen de la ciudad. Si es escribano será muy perjudicial para los pobres porque es amigo de hacer peticiones, muy codicioso y amigo de la plata. Por sus inquietudes le habían llevado preso de Mompox a Cartagena y también le habían expulsado de Santa Marta. ${ }^{11}$ Un rasgo añade este testigo, el de ser codicioso y amigo del dinero.

Francisco Patiño lo conoce de siete años y ha hablado muchas veces con él. Es soltero, no tiene casa ni bienes muebles o raíces, sino sólo su persona, y anda de un lugar a otro. Ha andado arrimado a Don Martín Polo y luego a Don Juan Polo, luego a Don Francisco Ximénez de Enciso y en Tenerife a Don Martín de Amoscótegui. No tiene constancia, ofende con sus razones, caviloso y amigo de pleitos anda siempre haciendo peticiones como si fuera letrado metiendo a los vecinos en pleitos. De escribano causaría muchos pleitos injustos, disgustos y diferencias.

Francisco de León, español, confiesa que siendo alcalde Don Francisco Ximénez de Enciso lo tuvo en su casa y lo conoció arrimado a Don Diego Polo y después a Don Juan Polo. No tiene vecindad fija ni bienes. Es inquieto, revoltoso y amigo de pleitos. Conviene al servicio de Dios que no se le dé título de escribano.

Pedro Durán de Cogollos, de 38 años, vecino del Valle y natural de Mompox lo conoce de hace 14 años y es de natural inquieto y revoltoso, amigo de pleitos y de meter en ellos a los vecinos.

El mercedario Fr. Jerónimo de Faria, lo conoce hace 13 años de Mompox, Tenerife y Cartagena de haber hablado con él muchas veces. Siempre ha oído decir que es hombre caviloso, inquieto y de natural revoltoso, amigo de meter pleitos y disgustos entre los vecinos de forma que con la mucha verbosidad que le acompaña alarga las causas y las enreda. Es servicio de Dios que dicho sujeto no sea escribano. ${ }^{12}$ Un nuevo rasgo de su persona, la mucha verbosidad, que tanto podía jugar en contra

\footnotetext{
9 Ibidem, imags. 84-85.

10 Ibidem, imag. 88.

11 Ibidem, imag. 91.

12 Ibidem, imags. 102-108.
} 
como a favor, dependiendo de la persona con la que tratara, pero que sin duda le servía para enredar y prolongar las causas con nuevas peticiones y recursos.

\section{LA ESGRIBANÍA DE CARTAGENA}

Si tanto era su empeño en conseguir una escribanía en Cartagena ¿en qué acabó la disputa entre sus aspiraciones y los contradictores que le ponían tantos obstáculos? No era un hombre que se rindiera ante las dificultades, pues pese a los informes tan negativos él contaba con apoyos en altas instancias, como la Audiencia de Santa Fe y el mismísimo Consejo de Indias. No se sabe cómo, pero contaba con dos cédulas reales que lo avalaban para ser examinado para el puesto de escribano público, que ya lo era en Mompox y algo de escribano había practicado en Cádiz. Alguna instrucción debía tener para atreverse a pleitear tanto, pues sus argumentaciones no eran siempre erradas. Teniendo cédulas del rey ¿cómo se atrevían unas autoridades locales a contradecirlas? No eran sólo las autoridades, pues algunas personas importantes se la tenían jurada.

Antonio del Castillo, regidor y presbítero manifestó enfáticamente que aunque se quedara solo, seguiría oponiéndose a Peñalosa. Esto opinaba del sujeto:

este mozo es el escándalo general de las Indias, al cual he sacado en hombros favorecido de los señores Gobernadores contra el sentir común de todos los señores tenientes generales y en medio de estas finezas me lo pagó de suerte y con tales circunstancias que es vergüenza referirlas y algunas tales que ni aun tomarlas en la boca se pueden; tanto por mi honra como por lo corrido que estoy de haber sido escudo de sus bellaquerías; yo le encargo a v. md. la conciencia y le advierto que en cuanto a lo que tocare al cabildo no lo conseguirá, aunque v. md. lo examine, porque cuando todos los demás mis compañeros vengan en ello, yo no vendré y para entonces sacaré la cara con todo empeño por lo que debo a este oficio que ejerzo y particularmente con los privilegios de fiel ejecutor. V. md. mire por esta república, por su paz y quietud. ${ }^{13}$

El caso más significativo seguramente fue el del maestro de campo Don Francisco Ximénez de Enciso, vecino de Mompox y residente en Cartagena, en cuya casa había vivido Peñalosa, al que tachaba de hombre rico y muy poderoso para mover las voluntades de los que mandaban. Pues Ximénez de Enciso decía que estaba dispuesto a gastar todo su dinero para impedir que Peñalosa se hiciera con una escribanía. Lo cierto es que el 2 de octubre de 1662 estando en la iglesia de los dominicos en Santa Marta, recién terminada la Misa, cuando todavía no habían abandonado el templo se produjo un incidente de cuchilladas entre el alguacil mayor, Don Diego de Mendoza y el maestro de campo, Don Francisco Ximénez de Enciso, aparentemente movido por Vicente de Peñalosa, que insistió ante el alguacil mayor

13 Carta de Don Antonio del Castillo al teniente general. Ibidem, imag. 112. 
que Ximénez de Enciso le había ofendido por haber presentado una petición en una causa que seguía Peñalosa junto con el alguacil. El incidente que no fue pequeño por haber sido en público y en lugar sagrado no podía separarse de la fama de Peñalosa de ser inquieto y pleitista, lo que impulsó al gobernador Marcos del Puerto, caballero de la orden de Santiago, a ordenar a Peñalosa que abandonara la ciudad y la provincia de Santa Marta en el término de 24 horas pues de lo contrario sería multado con 200 pesos y, si persistía en la desobediencia, sería puesto en prisión. Peñalosa nunca era partidario de callarse, de modo que argumentó que todo había sido una calumnia contra él, lo que anulaba el auto del gobernador. El asunto, según él, debía volver al juzgado natural del alcalde ordinario de la ciudad, porque, además, la condena de exilio nunca se le había notificado ni admitido su defensa, como establece una regla básica del derecho sin la cual todo el proceso era nulo. Si se le había hecho responsable de la reyerta en la iglesia, más se debía a la impugnación maliciosa de Ximénez de Enciso y, como consecuencia, la orden de expulsión, al no haber sido sentenciada, era nula y no podía ejecutarse, pues supondría expropiarle de un derecho.

El escrito y las argumentaciones de Peñalosa no podían ser interpretados por el gobernador sino como desacatos y desvergüenzas, por lo que ordenó ponerlo en prisión justificándolo con que el gobernador estaba actuando como juez, que allí no había litigio sino una sentencia a ejecutar, mientras que Peñalosa, como era su costumbre, pretendía seguir haciendo peticiones y alargar indefinidamente el pleito. Acababa, para remate, poniendo en duda la imparcialidad del teniente general y del escribano, a los que recusó.

Con el consiguiente enfado, el teniente general ordenó al gobernador de las armas, Don Ignacio Álvarez de Perea que detuviera a Peñalosa y lo pusiera en el castillo de San Vicente con prisiones. ${ }^{14}$ Indudablemente, Ximénez de Enciso y Peñalosa se conocían bien después de haber estado este último alojado en la casa del primero, sabían de las debilidades de cada uno y se las echaban en cara. A pesar de que se temía algún ataque a la ciudad, como había ocurrido en Ríohacha, y se necesitaba la colaboración de todas las personas, el gobernador mantuvo la sentencia de destierro para Peñalosa, que pedía se le diera por escrito la sentencia de destierro por diez años, aunque mientras tanto se había refugiado en el convento de Santo Domingo. El obispo, Don Francisco de la Trinidad Arrieta, manteniendo que no se le podía sacar por la fuerza estando acogido a sagrado, compartía la decisión del gobernador de desterrarlo por las condiciones del acusado y para garantizar la paz pública. Ante la nueva petición de que se le diera la sentencia de destierro por escrito, el gobernador contestó a esa insolencia que no había causa ni litigio, sino una decisión sumaria que debía cumplirse sin más.

14 Ibidem, imags. 113-127. 
Hubo alguna confusión acerca de las cédulas, que Peñalosa había mostrado al escribano Bartolomé de Salinas, aunque no las había dejado en la escribanía a disposición del teniente general para poder decidir el caso. Después de algunas gestiones, Peñalosa mostró las cédulas, que no ofrecían duda. El rey lo señalaba por su nombre y se dirigía al teniente general de gobernador, Ldo. Don Lope de Cevallos Barreda para que examinara al susodicho del oficio de escribano y notario público de las Indias, Islas y Tierra Firme del Mar Océano, adjuntando el título y provisión para que presentándose y demostrando tener habilidad y suficiencia y constando ser fiel y legal y jurando que no llevaría derechos excesivos a los pobres ni de las escrituras tocantes a los servicios de administración o de real hacienda, le entregaréis el dicho título para que pueda usar de él. Dado en Madrid, a dieciséis de enero de 1664. La otra real cédula de la misma fecha es más prolija porque el rey Felipe IV manda a su hijo el príncipe Carlos José y a todas las autoridades y dignidades especificando una por una todas las que se podía encontrar de todas las ciudades, villas y lugares para que guardaran con él todas las honras, mercedes, franquicias, libertades, preeminencias, prerrogativas e inmunidades que por razón del dicho oficio debía usar y gozar sin que le pongan traba alguna porque le da poder de usar dicho oficio. Le otorga un signo como su sello que deberá usar. Le ordena, eso sí, que no signe ningún contrato para el que se exija juramento, salvo aquellos contemplados por las leyes, ni haga contrato alguno en que se obligue en buena fe sin mal, engaño o por donde lego alguno se someta a la jurisdicción eclesiástica, porque si lo hace habrá perdido el oficio. ${ }^{15}$

El deber del teniente general consistía en comprobar que el candidato era de buena vida, fama legal y confianza de modo que hallándolo hábil y suficiente con el testimonio de tres testigos, lo admitiera al oficio. No tuvo problema el aspirante en encontrar los tres testigos, que fueron los escribanos Diego de Baena y Jerónimo de Salcedo, más el oficial mayor del oficio de escribano Juan Suárez, que por supuesto lo declararon hábil y suficiente para el oficio. Pero el procurador general Uriarte siguió insistiendo en que no podía admitirlo por los testimonios tan negativos que se habían presentado que lo descalificaban. Tampoco ahí se rindió Peñalosa, antes argumentó con una carta haciendo hincapié en que no se juzgaba a la persona, casi concediendo que era indeseable, sino sus habilidades y capacidad para el oficio. La vida y costumbres eran competencia del fiscal, máxime cuando juzgaba que las contradicciones de Uriarte eran calumnias contra su persona. Incluso las juzgaba como presiones que le hacía al procurador el maestro de campo Ximénez de Enciso, su enemigo, concediéndole esa baza al hombre rico y poderoso. Por el contrario, él presentaba testimonios de prelados, caballeros y gente importante que no entendían lo que se estaba obrando con él, testimonios que no aparecen por ninguna parte. Al procurador, decía Peñalosa, no le movía el celo por la justicia ni el bien de la república, sino en ese momento, como estaba Peñalosa enemistado con Ximénez

15 Ibidem, imags. 177-181. 
Enciso, la componenda con su enemigo, por lo que planteaba contradicción a su llegada al oficio. Además, la competencia del caso correspondía al alcalde ordinario de la ciudad, por lo que recusaba al juez y solicitaba se le examinara y recibiera como escribano y notario según ordenaban las reales cédulas. No se vuelve a mencionar el tema de la escribanía.

\section{EL CABILDO, UN AVISPERO}

Si al principio de la década de 1670 los problemas del cabildo habían girado en torno a las malas relaciones con el gobernador Ulloa, a finales de la misma se centraban en el monopolio que habían establecido los hermanos Mirafuentes, Diego como depositario general y Martín como alguacil mayor, junto con Vicente de Peñalosa, muñidor de tantas reclamaciones, Juan de Rada, Diego de Matute y Pedro de Zárate. Así procedían monopolizando las decisiones del cabildo y volviendo inútil cualquier control de la autoridad superior:

que los dichos Mirafuentes están coadunados con Pedro de Zárate, Don Diego Matute, Don Juan de Rada y Vicente de Peñalosa, que este los tiene dispuestos a su dictamen en los cabildos que se ofrecen, de tal manera que tuvo disposición a mover el ánimo al castellano D. Juan de la Rada siendo fiel ejecutor, el que embarazase a s. md. [de la Rocha] las visitas de carnicerías, panaderías y otros puestos. ${ }^{16}$

\section{El testigo D. Fernando de Llarena y Cabrera manifestó}

el veinte de agosto pasado de este año [1679] yendo este testigo para su casa como a las siete de la noche por la puerta de la casa donde vive dicho Vicente de Peñalosa, vido salir de ella dos hombres embozados que no pudo conocer quiénes eran, a los cuales les oyó decir este testigo: presto haremos cabildo contra su merced y daremos gusto a Peñalosa. ${ }^{17}$

En esta ocasión el objetivo de sus invectivas fue el teniente general Domingo de la Rocha Ferrer, abogado de los reales consejos y auditor de guerra que planteó una limpieza del gobierno municipal comenzando por la inspección del mercado, donde los pesos -debía ser bastante común- se hallaban trucados para sisar algo de materia en cada despacho. La táctica habitual del grupo municipal consistía en reclamar las decisiones del teniente general al gobernador ya que no se perdía nada con ello, porque a veces les daba la razón. Cuando menos, con las peticiones, reclamaciones e impugnaciones los procesos se alargaban y las autoridades

16 Ibidem, imag. 226.

17 AGI, Santa Fe, 45, R. 3, N. 48, imag. 240. Información de testigos, Cartagena, $1^{\circ}$ sept. 1679 
y asimismo Vicente de Peñalosa, que por estar su merced procediendo contra él por su mal obrar, siendo en esta ciudad quien mueve las competencias, como en el caso presente, influyendo a Don Diego de Mirafuentes, Antonio de Subiza, alcalde ordinario, para que lo tenga en el Tribunal de la Santa Inquisición. ${ }^{18}$

La guerra entre el teniente general de la Rocha y Vicente de Peñalosa debía estar declarada en los términos más duros que se pueda imaginar, pero para hacer una inspección más clara ordenó el primero tomar declaración el $1^{\circ}$ de septiembre de 1679, al licenciado Don Francisco Ramírez de la Cueva, de 47 años, quien manifestó ser público y notorio "que están abandarizados alguna parte de los regidores con Vicente de Peñalosa, el cual los instruye para que en los cabildos hagan las proposiciones a su modo". ${ }^{19}$ Todos profesaban enemistad con de la Rocha: Diego de Mirafuentes porque los fiadores para su cargo de depositario general, le habían retirado sus fianzas; Juan de la Rada, por una enemistad antigua del teniente general con su padre, intentó impedirle la entrada en las carnicerías lo que motivó que le pusiera preso en un castillo; Diego Matute y Alonso de Somovilla Tejada por un pleito que tuvieron sobre una negra de mala entrada; Martín de Mirafuentes porque quiso que le pagasen más de las décimas que le tocaban; José de Mesa Cortés tenía enemistad porque el teniente general no había atendido una súplica que le había hecho para que le quitara a su tía María José de Padilla el pago de una sentencia contra ella de 200 pesos y habiendo acudido al gobernador, este confirmó la sentencia de su asesor legal, el teniente general; en cuanto a Peñalosa, esto fue lo que declaró:

y Vicente de Peñalosa tiene la misma enemistad con su merced por no haberle admitido en su casa por haber entendido (y ser público y notorio) ser un hombre sedicioso, revolvedor de la república, inquietador de tribunales, solicitando las causas para poder defenderlas y por este camino estafar a las partes pidiendo cantidades gruesas de plata con color de decir que eran para los jueces para que diesen buena sentencia; y se comprueba todo lo referido que de seis años a esta parte que está en este ciudad, habiendo venido pobre de la villa de Mompox, desnudo como lo vido este testigo, ha adquirido (por estos medios de pleitos y enredos que hace) más de diez piezas de esclavos y plata sin tener otro oficio ni beneficio que el referido y, finalmente, es hombre de mal natural amenazando a su merced y a muchas otras personas y por ello no ha cabido en la ciudad de Santa Marta, en Río de la Hacha, en la Villa de Mompox y Tenerife, donde ha salido desterrado por ignominiosas causas que le han hecho, como de ellas constará y que Don Ambrosio de Arévalo, Don Miguel Pérez de Villena y Don Lope de Cevallos siendo tenientes generales en esta ciudad ha oído decir este testigo públicamente, le hicieron causa al dicho Vicente de Peñalosa y lo tuvieron preso por

18 Ibidem, imags. 213-214.

19 Ibidem, imag. 231. La pandilla la formaban estos siete: Diego y Martín de Mirafuentes, Diego Matute, Pedro de Zárate, Vicente de Peñalosa, Juan de la Rada y Alonso de Somovilla Tejada. 
sus inquietudes y alborotos que causaba a esta República y esto que ha declarado es la verdad so cargo de su juramento en que se afirmó y ratificó. ${ }^{20}$

No era nada nuevo. De la Rocha lo había advertido desde el principio, admirado de que habiendo sido rechazado para escribano y habiendo sido desterrado de varios lugares, detenido en varias ocasiones y creado tantas sospechas, hubiera sido admitido como regidor de Cartagena. Así estaban las cosas en una ciudad dividida tanto como su cabildo, porque al teniente general apoyaban sectores muy respetables de la ciudad, como el propio obispo, que se expresaba en estos términos después de elogiar el acierto del Consejo de Indias en nombrar a este teniente general:

con su venida han logrado los pobres el remedio de su justicia y los ricos y poderosos juez que castigue sus desórdenes, que habiéndolos grandes en los bastimentos y sustento de esta ciudad, los ha redimido visitando las carnicerías, panaderías y demás puestos en que se cometían graves daños a esta república sin que hubiese persona que se moviese a ejecutarlo hasta ahora. ${ }^{21}$

El obispo concluía con que no le eran muy afectos los regidores ni todas aquellas personas que tenían deudas y no pagaban, a los que el teniente general ha obligado a pagar obrando con rectitud y justicia.

Los frailes franciscanos por medio de su guardián, Fr. Salvador Montero, destacaron en el teniente general no sólo que atendió sus demandas y su amparo como pobres que eran, sino sobre todo que había desempeñado el ejercicio puntual y continuo de su cargo en bien de la república. ${ }^{22}$

El comendador de la orden de la Merced, Fr. Antonio de Torres ponderaba

la rectitud y el cristiano obrar del licenciado Don Domingo de la Rocha Ferrer, Teniente General de esta Ciudad de Cartagena, por ver en ella premiado lo bueno y castigado lo malo, siendo sus ocupaciones tan en servicio de Vra. Magd. que sólo atiende a dar Justicia con tanta igualdad que el rico no supera al pobre, sino sólo da la razón a quien con ella se presenta en su juicio. ${ }^{23}$

El Prior y Vicario Provincial de la orden de San Agustín, Fr. Lucas de Cárdenas todavía fue más allá en los elogios al teniente general Rocha

20 Ibidem, imags. 233-235.

21 AGI, Santa Fe, 45, R. 3, N. 48, imag. 251. Obispo Antonio Sanz Lozano a S.M., Cartagena, 30 ag. 1679.

22 AGI, Santa Fe, 45, R. 3, N. 48, imag. 255. Comunidad franciscana a S.M., Cartagena, 31 ag. 1679 .

23 AGI, Santa Fe, 45, R. 3, N. 48, imag. 263. Comendador de la Merced a S.M., Cartagena, 2 sept. 1679. 
El cabildo de Cartagena de Indias, una pandilla dominada... - J.B. Ruiz Rivera

cuyo desvelo y cuidado en la obligación de su oficio hemos visto tan celoso, desinteresado y puntual que los pobres y desvalidos saben ya que hay Justicia que los ampare y el bien común se halla preferido al particular, de que sólo gozaban los Ricos y los Poderosos, porque asistiendo personalmente a Panaderías, Carnicerías y demás mercados Públicos, en que eran interesados algunos Particulares, que a espaldas de esta obligación sólo atendían a sus mayores conveniencias a costa de la penuria y carestía de los demás: vemos hoy igual para todos el peso y la medida. ${ }^{24}$

De ninguna manera puede sonarnos extraño este enfrentamiento entre los poderes provincial y municipal con esos tintes de sospecha de abusos y corrupción. De Peñalosa se ha recopilado una colección de opiniones generalizadas muy negativas sin que ninguna fuera más allá de decir en el lado positivo que era hábil y suficiente para el cargo de escribano. ¿Qué sabemos, por otro lado, del licenciado de la Rocha?

De la Rocha se vio envuelto en el grave asunto de las monjas clarisas en que circularon excomuniones a diestro y siniestro. El obispo Miguel Antonio de Benavides para hacerse con el control del monasterio utilizó la excomunión de las autoridades civiles entre las que se encontró el teniente general del gobernador Rafael Capsir. Según algún testimonio, por las tardes rondaba el monasterio a caballo en una especie de cortejo a una novicia que correspondía agitando un pañuelo por la ventana, aparte de las visitas en el locutorio. El obispo Benavides acusó al teniente general de inoperante y corrupto por dictar sentencias viciadas y de vivir con mujeres casadas, aunque conocida la pasión del obispo, su testimonio puede adolecer de parcial.

\section{DOMINGO DE LA ROCHA FERRER}

Domingo de la Rocha provenía de la isla de Tenerife, aunque se graduó en la Universidad de Salamanca, de Bachiller en Cánones el 21 de abril de 1666 y de Licenciado en el mismo Derecho el 20 de agosto de 1669 y allí ejerció la docencia durante seis años explicando los cuatro libros de Instituta. El cabildo de su isla natal lo recomendó por su mucha calidad y por ser descendiente de los primeros conquistadores de Tenerife y La Palma. El 6 de julio de 1677 se le despachó el título de Teniente General de la gobernación de Cartagena y Auditor de la gente de guerra por un período de cinco años. ${ }^{25}$ No lo debió hacer tan mal como le acusaba el obispo Benavides cuando fue promovido a oidor de la Audiencia de Santa Fe.

En Cartagena claro que debía ser un partido muy codiciado hallándose en 1683 con treintaicinco años o algo menos, con una inteligencia aguda y valor para hacer frente a las realidades por más adversas que fueran. En Cartagena emparentó con

24 AGI, Santa Fe, 45, R. 3, N. 48, imag. 267. Prior y Vicario Provincial de San Agustín, Cartagena, 4 sept. 1679.

25 AGI, Indiferente, 130, N. 3. Méritos de Domingo de la Rocha, 
una de las familias destacadas. Aquella novicia de las clarisas se convertiría en su mujer. Llevaba el apellido de Labarces de su padre Don Antonio, contador oficial de la ciudad en el último cuarto del siglo, casado con Micaela de Pando. El matrimonio no dio más que hijas, a las que situaron con lo más florido de la ciudad. Catalina de Labarces y Pando casó con Don Toribio de la Torre, factor de la Real Hacienda, que obtuvo el título de conde de Santa Cruz de la Torre. (Castillo Mathieu, 1998, p 74) Otro personaje de larguísima duración en la ciudad y de trayectoria destacada como alcalde del castillo de Bocachica y héroe de la resistencia contra el asalto de Pointis, Sancho Ximeno de Orozco, casó con otra de las hijas. Domingo de la Rocha Ferrer fue el tercero en llevarse a la más joven, Juana Clemencia de Labarces y Pando, que había estado algunos meses en el convento de Santa Clara y con motivo de los alborotos entre las autoridades religiosas del obispo y de los franciscanos, y de los enfrentamientos entre la autoridad civil y la eclesiástica dejó el convento para casarse con el que era teniente general de la provincia. Cuando se mudó como oidor a Santa $\mathrm{Fe}$, la situación matrimonial no resultaba muy natural ni normal, porque su mujer no había dejado Cartagena. Ese incidente pasajero no les impidió tener numerosos hijos, algunos de los cuales destacaron, en concreto, Francisco llegó a presidente de la Audiencia de Santo Domingo, Domingo a arzobispo de Santa Fe, Vicente fue canónigo en la catedral de Santa Fe y José Joaquín gobernador de Antioquia. En cualquier instancia de la ciudad, como lo expresaba el visitador Francisco Carcelén, tenía de la Rocha "extendidos parientes", además de "dependencias por lo grueso de sus caudales y de la amistad, parcialidad y correspondencia que tiene con Don Sancho Ximeno."26

Sin embargo, no le faltaban enemigos a esta autoridad, pues durante los días más duros de las excomuniones del obispo Benavides, Juan Bautista Rapalo acusaba a Domingo de la Rocha de ir transportado en silla de mano -no perdamos de vista los rigores del calor de Cartagena- acompañado de cuatro pajes y el alguacil. ${ }^{27}$ Una vez más se enfrentaban dos posiciones contrapuestas, a favor y en contra del obispo y ¡qué casualidad! Peñalosa estaba de parte del obispo y alegaba que le habían tratado mal por ese hecho de posicionarse con el prelado. ${ }^{28}$

Los enfrentamientos entre el teniente general y varios miembros del cabildo tuvieron episodios concretos que afectaban a las familias o a la servidumbre alegando en general que esos casos no eran competencia del letrado de la Rocha. Uno se produjo en Timiriguaco, donde dos individuos mataron a un negro libre, Pedro Ramírez, el día de San Juan, 24 de junio de 1679. El alcalde de la Santa Hermandad Fernando Álvarez de Burgos ordenó hacer las pesquisas necesarias. El alcalde

26 AGI, Santa Fe, 47, r. 1, n. 14c Copia de Fco. de Carcelén sobre los inconvenientes de Domingo de la Rocha, 26 oct 1688.

27 AGI, Santa Fe, 257, cuaderno 13. Testimonio de los autos hechos en razón de las personas que estando excomulgadas y fijadas en la tablilla se andan paseando públicamente por las calles. Cartagena, 23 feb. 1683.

28 AGI, Santa Fe, 259. Carta de Peñalosa a S.M., Cartagena, 9 oct. 1683. 
ordinario por hallarse achacoso delegó en un comisario para las averiguaciones, pero se metió por medio el teniente general contra el que opusieron la jurisdicción de la Santa Hermandad. Una cédula antigua otorgaba competencias al alcalde provincial porque cuando la cédula se había emitido en 1642 había 600 cimarrones que ponían en peligro las estancias y a sus dueños. El gobernador Capsir dio la razón a Álvarez Burgos justificando la competencia de la Santa Hermandad, ${ }^{29}$ aunque la muerte de Pedro Ramírez, según su hermano Simón, no había sucedido en despoblado -jurisdicción de la Santa Hermandad- sino en el poblado de Timiriguaco.

Dña. Ana María Cid Cuadrado propietaria del hato del Rosario en la jurisdicción de San Benito Abad debía a su mayordomo, Juan Sobrino, 177 pesos, que reclamó ante el teniente general. El marido de la propietaria, Diego Pretel, elevó una instancia ante el alcalde ordinario Miguel José de Barona. La Audiencia, sin embargo, sentenció que la Sra. Cid Cuadrado debía pagar los 177 pesos y prohibió cualquier otra injerencia bien del teniente general, bien del alcalde ordinario. Otro caso en que de la Rocha quedó desautorizado por el gobernador Capsir tuvo como protagonista a Dña. Clemencia Ladrón de Guevara madre de Juan Padilla, al que reclamaba una tal María Josefa la sexta parte de sus bienes acusándolo de que era su padre. A pesar de haber sido rechazada la demanda, el teniente general exigió a Dña. Clemencia 200 pesos de litis, que rechazó el gobernador.

\section{DE LA ROCHA OIDOR EN SANTA FE}

Ya en Santa Fe su ejecutoria fue objeto de inusuales alabanzas de diversos cuerpos, como la comunidad de San Agustín a cuyo frente se encontraba el prior Fr. Sebastián Serrada:

Vive esta Religion con el reconocimiento de todas las prendas del Dr. D. Domingo de la Rocha Ferrer, oidor de esta Real Audiencia, cuya integridad en la Administración de Justicia notoria a todo este Nuevo Reino con su puntualidad y asistencia continua, limpieza en el manejo de negocios, doctitud para la inteligencia en los más arduos, piedad para favorecer a los desvalidos, valor para la ejecución de la Justicia y humanidad con los pleiteantes y afabilidad con todo el resto de gentes y personas en medio de lo decoroso de su gravedad ha de poseer un ministro por todas partes expectable y digno de mayores empleos en la magnificencia de V. Magd. Todo lo cual si callara esta Religión y omitiera informar a V. Magd. con razón debiera reprenderse de remisa en el deseo que le asiste del servicio de V. Magd. y que logra su Real Corona en los buenos y excelentes ministros (siendo uno de ellos el referido oidor por su inteligencia, aplicación y virtud) razones exigidas que mantengan con su gobierno la monarquía y con celo la paz y aumento en los estados de V, Mgd. ${ }^{30}$

29 AGI, Santa Fe, 45, R. 3, N. 48, imag. 19, cit.

30 AGI, Santa Fe, 61, N. 98. Comunidad de San Agustín a S.M., Santa Fe, 22 feb. 1697. 
Sin embargo, esta opinión no fue unánime porque también tuvo contradictores. Uno de los más destacados fue el oidor y juez visitador Juan Garcés, de quien dice el afectado ser su enemigo acérrimo. Para la investigación del Presidente Cabrera y el oidor de la Rocha fue nombrado el oidor de Santo Domingo que iba con ese puesto a Panamá, Fernando de la Riva Agüero, que le exigió mientras durara la visita ir exiliado a Popayán, que distaba 200 leguas por caminos escabrosos de montaña, ríos caudalosos y rigurosísimos páramos, diciendo la cédula no saliese de dicha ciudad hasta que se mandase otra cosa. A 30 leguas de Santa Fe enfermó de unas calenturas que le tuvieron al borde de la muerte sin médicos ni medicinas, donde estuvo retenido por tres meses hasta poder levantarse de la cama y buscar una tierra menos caliente. El asunto que le perseguía ¿era resultado de su gestión como oidor en Santa Fe o se arrastraba desde el oficio de teniente general en Cartagena? ${ }^{31}$

En esta persecución no se vio solo, pues le tocó compartirla con el presidente de la Audiencia Don Gil Cabrera y Dávalos, haciéndole partícipe de los supuestos abusos de los que les acusaban los oidores Juan Garcés, Fernando López de Dicastillo y Antonio de la Pedrosa, que manejaban la Audiencia. El presidente Cabrera fue apartado a Cartagena mientras de la Rocha, que había gobernado en Cartagena de teniente general, fue enviado en dirección contraria. ¿A quién habrá que creer? Por sus hechos los conoceréis. No perdamos de vista a Vicente de Peñalosa que sin duda tenía sus conexiones con los oidores de la Audiencia de Santa Fe. De la Rocha, a diferencia de Peñalosa, era un hombre ordenado con su familia estable. En 1691 ya tenía seis hijos pequeños y otro a punto de nacer cuando le dieron ocho días para abandonar Santa Fe. Peñalosa iba sólo sin compromisos de familia. ¿Qué negocios le enfrentaron a de la Rocha con los oidores de Santa Fe? En una carta del oidor Juan Garcés de 5 de abril de 1692 una anotación del Consejo dice: "A D. Gil de Cabrera y a D. Domingo de la Rocha Ferrer se ha mandado se les ponga en el ejercicio de sus puestos sin perjuicio de lo que resultare de los autos de esta pesquisa. Consejo a 2 de diciembre de 1693. Al Fiscal" ${ }^{\prime 2}$

Todo hace pensar que como hombre recto no convino con los negocios que manejaban, en los que de alguna manera se enredó el presidente Cabrera que luego no los pudo parar porque lo tenían atrapado en su red. No le valió, por tanto, su tolerancia con ellos a la hora de investigarlo y suspenderlo. ${ }^{33} \mathrm{~A}$ de la Rocha le hicieron pasar un tormento de meses, a punto de perder la vida, con la mitad de su sueldo embargado teniendo que alimentar a esposa y siete hijos y aguantando las cartas y testimonios falsos de sus enemigos, que actuaban por venganza ya que no entraba en su juego ilegal.

31 AGI, Santa Fe, 33, R. 1, N. 1. Domingo de la Rocha Ferrer a S.M., Cartagena, 4 jun. 1692.

32 AGI, Santa Fe, 59, N. 16, imag. 74. Juan Garcés de los Fayos a S.M., Santa Fe, 5 ab. 1692.

33 AGI, Santa Fe, 33, R. 1, N. 1, imag. 8. Domingo de la Rocha Ferrer a S.M., Santa Fe, 4 jun. 1692. 
Pero, de la Rocha supo responder y desenmascarar los manejos turbios de esos supuestos jueces. Garcés entró en conflicto con el Presidente por unas pugnas familiares entre el protector de naturales, Antonio de la Pedrosa y su hermano Manuel de la Pedrosa, que hasta se quisieron matar. Garcés era íntimo amigo de Antonio, su padrino de boda y quien había arreglado el enlace. "No quise seguir sus dictámenes", confiesa de la Rocha, al que quisieron meter en sus negocios, no habiendo podido probar en él ningún cohecho ni baratería, mientras que Garcés tenía el monopolio del oro en la Montuosa alta y baja, [minas de Pamplona] de modo que los mineros no podían enviar el oro a la Casa de la Moneda, porque Garcés tenía un sobrino y dos criados en las minas que lo controlaban todo y cualquier denuncia moría en la Audiencia sin ser atendida. Algo parecido sucedía con las esmeraldas en Muzo, donde tenía a dos hermanos, Dionisio y Antonio Villaliaño, que hacían mil extorsiones a los vecinos sacándoles deudas, si no colaboraban en sus designios. Debajo de la vivienda del oidor de Dicastillo tenía Garcés tiendas que llevaban particulares en su nombre como era de conocimiento general. ${ }^{34}$

En cuanto a Carcelén, las dos cartas que había escrito contra él le daban la oportunidad de defenderse. Carcelén se dedicaba al comercio a gran escala pues en la armada del general Gonzalo Chacón había llevado más de 1.000 botijas de vino de que tuvo un litigio con su confidente, al que intentó excluir del reparto de beneficios. En Santa Fe las vendió con ayuda de José Ricaurte, tesorero de la Casa de la Moneda y con el producto obtenido, los ahorros de su sueldo y los 25.000 pesos que pidió prestados se dedicó al comercio de cera, telas y otros géneros teniendo mercaderes para su negocio tanto en Sanlúcar de Barrameda como en Santa Fe. En un remate de Cortes de Puntas celebrado en Cartagena se lo llevó él por medio de un testaferro, privando con ello a la real hacienda de muchos pesos. A tanto llegó, que el presidente recibió cédulas para investigar el caso, pero Carcelén logró sonsacar a Cabrera las cédulas que le encargaban investigarlo de forma que cuando se celebró la audiencia con testigos, estos estaban preparados para responder lo que le convenía con resultado totalmente negativo para la investigación, porque todo el mundo reconocía que era Carcelén un protegido del Presidente. ${ }^{35}$

El oidor de la Rocha siguió recibiendo el apoyo de los sectores más respetables, como el de los franciscanos, que tras ponderar la obediencia que había mostrado a su destierro sin que se produjera el más mínimo alboroto, con el apoyo de eclesiásticos y seculares hasta el último de la plebe, concluía la comunidad seráfica:

sin que hubiese más que unos vivos y eficaces deseos de que el Dr. D. Domingo de la Rocha Ferrer volviese al ejercicio de su plaza de oidor más antiguo de esta Vra. Real Audiencia por la falta que prácticamente se había experimentado hacia su persona en la judicatura de su oficio, por haber sido un ministro de gran justificación, pureza y

34 Ibidem, imag. 6

35 Ibidem, imags. 8-9. 
desinterés en sus operaciones, sin tener en esta ciudad pariente ni deudo de quienes se pudiese recelar ni la más leve inquietud. ${ }^{36}$

Los dominicos, por su parte, criticaron al juez Fernando de la Riva Agüero por haber dejado la causa sin sentenciar cuando no era eso lo que se le había ordenado en la cédula, alargando innecesariamente el proceso con su remisión del atestado al Consejo de Indias. Con la petición de que de la Rocha fuese restituido a su cargo de oidor más antiguo al experimentar muchos la falta de su buen obrar, manifestaban "su gran justificación, limpieza y desinterés, no moviéndole a ello otra cosa que su cristiano y piadoso celo." ${ }^{37}$ La comunidad agustina con muy medidas palabras por lo que podía significar salir en defensa de un juez, destacaba en este caso tratarse de un juez caído, al que reclamaban que volviera de su exilio porque era necesario. ${ }^{38}$

Algo que no había aparecido ni podíamos sospechar en una junta del Consejo de Indias de 10 de enero de 1695 se condena a una reprimenda por parte del Presidente de Santa Fe al oidor de la Rocha "por haber tenido diferentes palabras descompuestas dentro del Acuerdo con D. Francisco López de Dicastillo de que resultó desafiar a este el dicho Rocha". Sin embargo, El Consejo no entró en el meollo de lo que se les investigaba a él y al presidente Cabrera. ¿Qué delitos eran los que les investigaban y en qué quedaron las averiguaciones? Nada de eso se dice.

\section{FINAL DEL CONTENCIOSO ROCHA-PEÑALOSA}

Volviendo a Peñalosa, de poco sirvieron los apoyos que recibió de la Rocha, porque en 1680 se dirigió al rey -el teniente general movido de la pasión contra él lo había acusado de alborotador- para ratificar la sentencia favorable en la Audiencia de Santa Fe de 11 de julio de 1680, adonde tuvo que desplazarse para su defensa, pese a su edad y los achaques que padecía, en que invirtió seis meses y muchos gastos. ${ }^{39}$ Por si esto fuera poco, también envió Peñalosa una petición al rey en parecidos términos solicitando que las costas del proceso fueran cargadas al teniente general por impedir a los cabildos dar cuenta libremente a su majestad. ${ }^{40}$ Lorenzo Matamoros en nombre del Sargento Mayor Vicente de Peñalosa, consiguió de la Audiencia en sentencia de vista y revista la absolución y puesta en libertad (llevaba cuatro meses en prisión)

36 AGI, Santa Fe, 33, R. 1, N. 1, imag. 21. Comunidad franciscana de Santa Fe, Santa Fe, 9 ab. 1692.

37 AGI, Santa Fe, 33, R. 1, N. 1, imags. 25-26. Comunidad dominica de Santa Fe, Santa Fe, 23 ab. 1692.

38 AGI, Santa Fe, 33, R. 1, N. 1, imags., 29-30. Comunidad agustina a S.M., Santa Fe, 11 en. 1692.

39 AGI, Santa Fe, 45, R. 3, N. 48, imags. 271-272 y 283. Vicente de Peñalosa a S.M., Cartagena, 27 sept. 1680 .

40 AGI, Santa Fe, 45, R. 3, N. 48, imags. 275-276. Petición de Vicente de Peñalosa, s.l./s.f. 
por el odio y mala voluntad que el teniente general Domingo de la Rocha Ferrer ha tenido y tiene con su parte, al haber procedido contra él criminalmente y pidió que su parte, que había sido condenado en costas, fuera exonerado de ellas y las pagara el teniente general, que suponían 519 pesos y 6 reales. ${ }^{41}$

¿Qué apoyos tenía Peñalosa tanto en Santa Fe como en Madrid para que tras los informes emitidos en Cartagena saliera exculpado? ¿Tanto pesaba la herencia familiar como para sanar todas sus tropelías y la conducta que practicaba en el cabildo de Cartagena junto con los secuaces de su pandilla? Porque sus tentáculos llegaban bien lejos en el Consejo de Indias en que al evaluar informes positivos del cabildo y de comunidades religiosas sobre el juez de la Rocha, el relator califica dichos informes de "haber sido solicitados mañosamente" y el fiscal los desautoriza porque existen canales oficiales para realizar tales informaciones. ${ }^{42}$

Un ejemplo de los informes positivos de las órdenes religiosas es el de los franciscanos del convento de Santa Fe:

en quien concurren todas las calidades, que constituyen y adornan un puro, recto y desinteresado Ministro, porque en el buen ejemplo es singular su recogimiento yendo solo de la Audiencia a su casa su continuo ejercicio, donde con particular aplicación disfruta de los libros, los aciertos de sus votos, la viveza con que asiste a la causa pública es notoria pues a ella se deben como oidor más antiguo las vistas de los negocios y el presto despacho de ellos en las funciones de Edificación de la República y causas piadosas de ella es el primero en las asistencias con especialísima piedad, a que induce la afabilidad con los vecinos sin que la interrumpa el ejercicio de la Justicia que con entereza invencible y con desinterés sumo administra. ${ }^{43}$

Podría pensarse que era fácil conseguir el apoyo de unos frailes bondadosos valiéndose de buenas palabras, pero es que en semejantes términos se expresaron los miembros del cabildo de la ciudad capital del reino más allá de los preparativos de defensa que tuvo que realizar en un período tan breve como trece días, porque el presidente se había desplazado a Honda con el mismo fin tras la toma de Cartagena por los franceses:

Es Ministro muy sabio, limpio, desinteresado y tan afable, político y cortesano que comúnmente arrastra las voluntades, alabándole todos en el expediente de los negocios y causas que pasan en la dicha Real Audiencia, a que es tan asistente que jamás falta de ella y de los Tribunales y Juzgados de su cargo, oyendo a las partes y consolándolas en sus pleitos, que determina puntualmente con muy cristiano celo en la administración de Justicia que rectamente administra sin que le muevan pasiones

41 AGI, Escribanía, 1.044, fols. 346-347. Real Ejecutoria de la Audiencia de Santa Fe, refrendada en Madrid, a 10 de junio de 1683.

42 AGI, Santa Fe, 61, N. 98. Cabildo de Santa Fe a S.M., Santa Fe, s.f.

43 AGI, Santa Fe, 61, N. 98, imag. 13. Comunidad franciscana a S.M., Santa Fe, 2 mar. 1697. 
ni intereses por ser Ministro temeroso de Dios y fomentador del culto divino y de tan linda naturaleza que a los mismos que en otra ocasión le capitularon y depusieron en contra suya continuamente los está acariciando y fomentando en sus conveniencias, cuyas demostraciones ocasionan el que este Ministro tenga en sus operaciones general aplauso no sólo de esta República sino de todo este Reino."

No sé si cabe otro comentario más que la virtud no siempre alcanza en esta vida su recompensa. Peñalosa parece que ganó en las camarillas de las dependencias gubernamentales, aunque entre el público al que gobernaba no tuviera esa aceptación, mientras que de la Rocha cumplía con su deber exigente de juez, recogido del contacto con el público para proteger su independencia y mostrando afabilidad en el difícil ejercicio de administrar justicia con imparcialidad. Sin olvidar que la administración también nos da algún buen ejemplo, como en el caso de Peñalosa, que aun teniendo cédulas reales para llegar a escribano, la oposición local razonada y argumentada se lo impidió según la fórmula tan real de que "se obedece, pero no se cumple."

\section{BIBLIOGRAFÍA}

Caño Ortigosa, José Luis (2019a). Los cabildos indianos: estado de la cuestión, fuentes y archivos para un necesario avance historiográfico. Revista Electrónica de Fuentes y Archivos (REFA), año 10, número 10, pp. 15-37.

Caño Ortigosa, José Luis (2019b). Las fuentes judiciales para el estudio de los Cabildos indianos. Temas Americanistas, 42 (junio 2019), pp. 192-213.

Castillo Mathieu, Nicolás (1998). Los gobernadores de Cartagena de Indias (15041810). Santafé de Bogotá, D.C.: Academia Colombiana de Historia. 
